\title{
Mine Water and the Environment: History Until Volume 40 and the New Cover Design
}

\author{
Christian Wolkersdorfer ${ }^{1}[$
}

Received: 21 June 2021 / Accepted: 14 July 2021 / Published online: 26 July 2021

c) Springer-Verlag GmbH Germany, part of Springer Nature 2021

\section{The Beginning}

This year, IMWA's journal Mine Water and the Environment is celebrating its 40th volume, and by the end of 2021, more than 1000 articles will have been published in this journal (author and article index on www.IMWA.info/authorindex and www.IMWA.info/articles). A total of 2299 authors contributed to these articles, ranging from Abaci et al. (1992) to Żurek et al. (2018).

It is a long history of ups and downs, which started with the journal's first issue in March 1982 (Fig. 1); at that time, the journal's title was the International Journal of Mine Water (www.IMWA.info/40th-anniversary-volume.html). It was initiated by the founding fathers of IMWA and the first Editor-in-Chiefs were Raghu Singh and Rafael Fernández Rubio (Wolkersdorfer 2002). From this year, until April 2000, it was self-published by the association. Between 1982 and 2000, issues of the journal were printed in Granada, Madrid, Budapest, Nottingham, Castro Verde, Wollongong, Denver, and Loveland. During that time, IMWA often did not have enough manuscripts; therefore, volumes 8,15 , and 16 never appeared in print. One of the reasons for this is that IMWA didn't have many members at that time, and the journal was not as well-known as it is today.

That situation changed substantially when the current Editor, Bob Kleinmann, became Editor-in-Chief during the Bled/Slovenia IMWA Congress in 1997. He was able to attract new authors to the journal, so that the journal could be published regularly and changed its name to Mine Water and the Environment. Still, the journal was mainly known primarily by the IMWA family, until the newly appointed IMWA councillor, Christian Wolkersdorfer, got in contact

Christian Wolkersdorfer

christian@wolkersdorfer.info

1 Department of Environmental, Water and Earth Sciences, Tshwane University of Technology (TUT), 175 Nelson Mandela Drive, Pretoria 0001, South Africa with the international publisher Springer (now Springer Nature) in 1999. During the Katowice, Poland Congress, Christian Witschel from Springer Heidelberg informed the IMWA EC about the details of the publishing process. This resulted in some long nights, where the Editor-in-Chief and the Technical Editor learned how to format the papers using MS Word to meet the Springer layout criteria. Eventually, this meeting resulted in a professional relationship between IMWA and Springer, with the first issue published in Berlin in December 2000.

\section{With Springer}

Mine Water and the Environment's first issue with Springer had to be published under extreme time pressure, as neither Bob Kleinmann (Editor-in-Chief) nor Christian Wolkersdorfer (Technical Editor) had sufficient experience in professional publishing of a journal. Indeed, until 2007, Bob Kleinmann and Christian Wolkersdorfer were typesetting all of the manuscripts in MS Word. Therefore, the issue was printed on a needle-printer at the Springer Berlin office and sent to the printing house Universitätsdruckerei H. Stürtz AG in Würzburg/Germany-the results, although a great improvement over the society-published issues - still left a lot of room for improvement. Another issue, which had to be finished under special conditions, was Supplement 1 to Volume 23 (March 2004). During formatting and proofreading of the text and figures, the hydrogeology department of TU Bergakademie Freiberg/Germany had to be evacuated because there was a danger that the roof would collapse. But even this Supplement was finished in time and sent to Springer for printing and shipping. Since then, the typesetting and final manuscript handling gradually improved; it is now done by SPS in India, which was sold by Springer to SPi Global at the end of 2019.

Though Springer applied immediately to the Institute for Scientific Information (now Clarivate Analytics) 


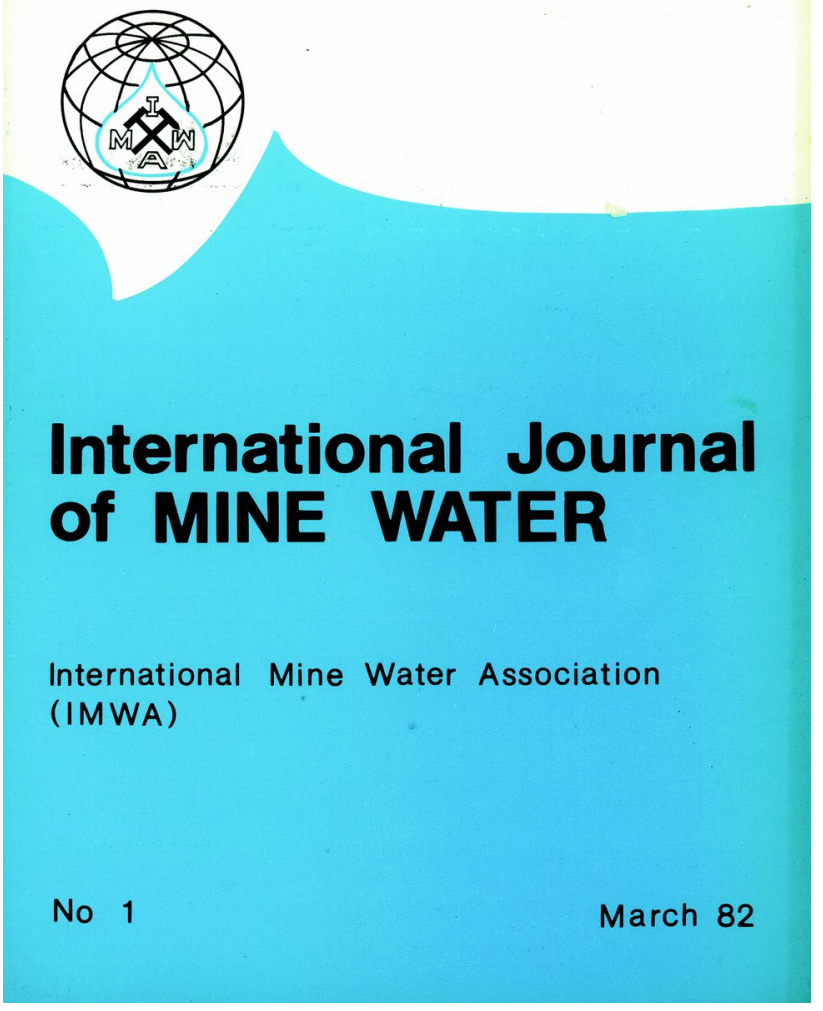

Fig. 1 Cover of the first issue of the "International Journal of Mine Water" with the original IMWA logo

to have the journal listed in the Science Citation Index, hoping to obtain a Journal Impact Factor (JIF) for Mine Water and the Environment, after three years of waiting, we missed the technical criteria by 20 citations (200 were needed). Therefore, we had to wait for another few years, until the journal got its first JIF in 2010 (Kleinmann 2020a), which was 1.039. This means that, on average, the journal's papers were cited in other journals more or less the same number of times as the number of articles it published. Since then, the number of manuscripts submitted and published have increased rapidly (Kleinmann 2020b), and the quality of the papers and the JIF have continued to improve. The journal's latest JIF is 2.883 , meaning that on average, the papers published in the journal the previous two years were cited in other journals about three times. During the year 2020, a total of 285 manuscripts were received, of which roughly $30 \%$ have been or will be published. Compared to the situation 16 years ago (Wolkersdorfer 2004), this is an improvement that Springer has been completely surprised by, as it is an extremely high JIF for such a specialized journal.

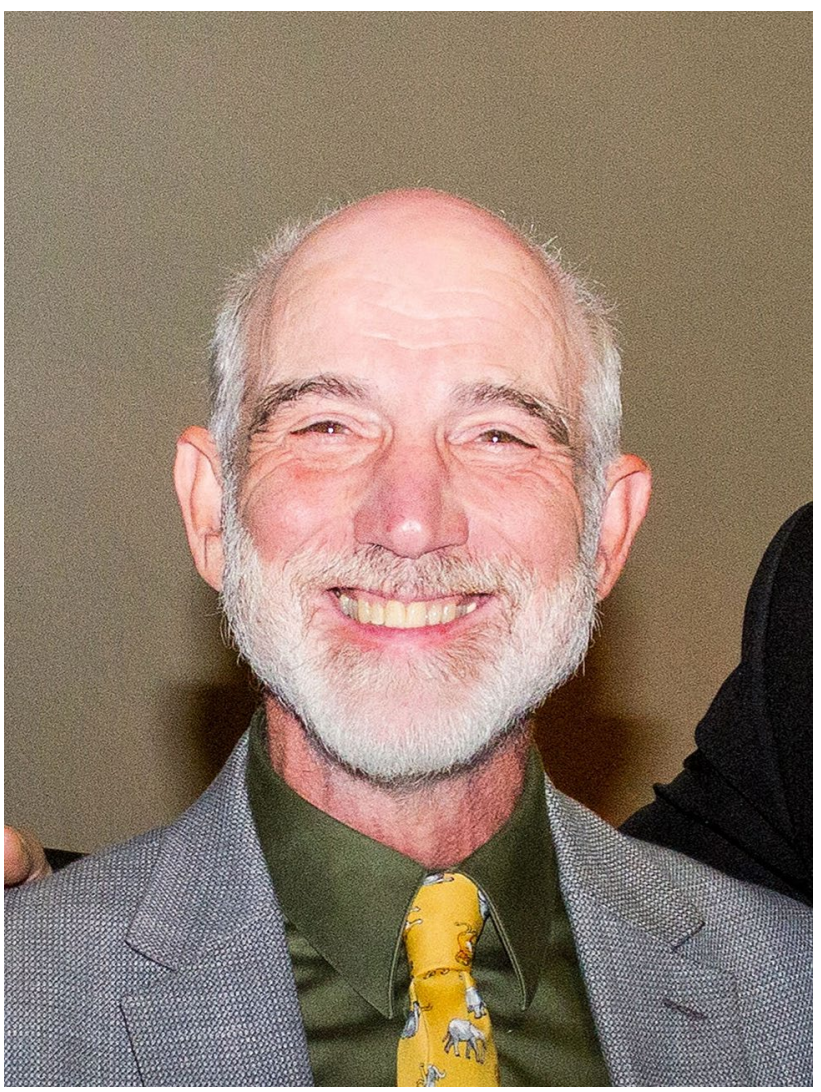

Fig. 2 Bob Kleinmann in 2018, after having been awarded with IMWA Honorary Membership

\section{Editorial Team, Authors and Reviewers}

Since the IMWA journal was found, it has had two Editorsin-Chief and five Assistant Editors. From 1982 until 1995, Raghu Singh was the Editor-in-Chief, assisted by Rafael Fernandez-Rubio from 1982 to 1988 and Donald Armstrong from 1991 to 1995.

Bob Kleinmann (Fig. 2) has served as the journal's Editor-in-Chief since 1998, supported by the assistant Editor Adrian Brown from 1998 to 2000 and Colin Booth from 2001 to 2007. Starting in 2017, Anne Weber became the journal's Assistant Editor. Beginning in 2000, Christian Wolkersdorfer has served as Technical Editor and Graphics Editor, and now serves as the Managing Editor. Between 2008 and 2011, the Graphics Editor was Romy Matthies, ensuring that the graphics quality was technically correct. Besides this core team, the journal currently has 32 Associate Editors and ten individuals who serve as the journal's International Editorial Board.

An additional reason for the journal's relevance is that the abstracts of all the papers are translated into three languages: Chinese, Spanish, and German. This increases the 
journal's visibility on the internet, consequently increasing the number of citations to the journal's articles. Nine colleagues (Changshen Wang, Jörn Geletneky, Helmuth Landsmann, Joscha Opitz, Walter Pohl, Martin Schultze, Wilfried Uhlmann, Kai-Uwe Ulrich, Edgardo Donati, and until recently, Michael Paul) have translated the English abstracts. This process is managed by Josepha Zielke.

Of the 2299 authors of the papers published between 1982 and 2000, the 10 most frequent authors are: RN Singh, Ch Wolkersdorfer, M Benzaazoua, B Bussière, JP Maree, R Hakkou, PL Younger, R Fernández-Rubio, CH Gammons, and RE Williams. Yet, the most cited papers, according to the Web of Science (WOS) are Li et al. $(2013 ; 124 \times)$, Skousen et al. $(2017 ; 106 \times)$, Li et al. $(2018 ; 90 \times)$, Mudd $(2008 ; 76 \times)$ and Prasad and Sangita $(2008 ; 70 \times)$. Unfortunately, $25 \%$ of the papers listed in the WOS have never been cited in any other journal evaluated in the WOS-which does not mean they are not cited in books, proceedings volumes, or journals outside of the WOS.

All of these papers could not have been published without the excellent work of nearly 1000 reviewers, of which 811 have helped since the journal has published with Springer/ Springer Nature. Of these, the 10 most active reviewers have been: Mohammad Valipour, Kevin Myers, Cleber Gomes, Miran Veselič, Kevin Morin, Martin Mkandawire, Broder Merkel, Donglin Dong, Andrew Johnstone, Li Bo, and Ben B. Faulkner. Together, these individuals reviewed $36 \%$ or 353 manuscripts.

As the quality of the journal increased, it was thought that the most excellent papers should be recognized, and the idea of a "Best Paper Award" evolved (Fig. 3). The International Editorial Board was given the responsibility of reading all of the journal's published papers and selecting the best. However, as the number of published papers continued to increase, the International Editorial Board had to read and evaluate more and more papers, until after seven years, they found themselves overwhelmed, and we made the difficult decision to stop giving out the award. Between 2008 and 2014, seven papers won an award, with the first authors being Bob Hedin, Natalie Kruse, Susanna Kihlmann, Anna Bogush, Hans van der Sloot, Santiago Jardón, and Ihssan Dawood (www.IMWA.info/imwa-awards/best-paper-award. html).

\section{Celebrating the 40th Issue}

As discussed above, the partnership with Springer Nature, the journal's world class editorial team (who all serve without any financial compensation), our outstanding authors and reviewers, and the journal's ranking in the Science Citation Index have all helped the journal to see its 40th birthday at the end of this year. To celebrate this birthday, the first

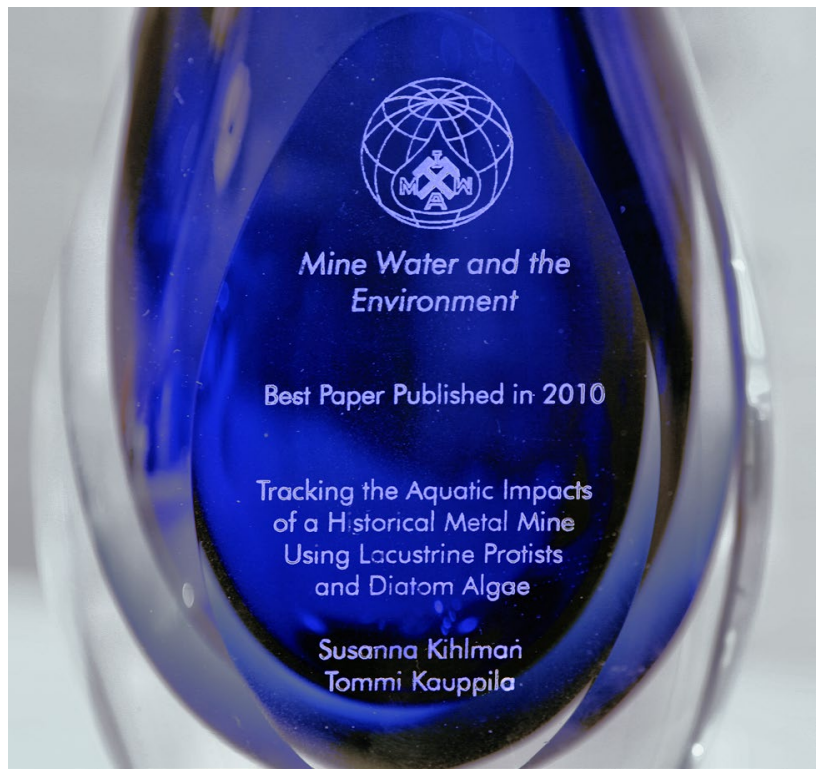

Fig. 3 "Mine Water and the Environment" best paper award 2010

issue this year was a special issue about tailings storage, guest edited by one of the journal's founders: Rafael Fernández Rubio, and the second was another special issue on mine water inrushes in China, guest edited by Wanfang Zhou, Shuning Dong, and Hao Wang. The following two issues will include some recollections (like this one), perspective papers, and success stories from our older IMWA members, along with as many of the normal technical papers as we can fit. However, the most obvious aspect of the 40th issue is the redesign of the journal's cover, including a new cover image.

\section{The Journal's New Cover}

More than 20 years ago, Bruce Dudgeon and Christian Wolkersdorfer designed the journal's previous cover (Fig. 4). Since then, until this year, the front image was from a German underground uranium mine and the back showed a mine dump from a German lignite mine. At that time, Springer wanted Mine Water and the Environment to complement their German journal Grundwasser [Groundwater]. Therefore, the cover designs were nearly identical. Yet, over the years, the editorial team of Mine Water and the Environment got a little bit tired of the blurry blue cover design, and several design proposals were made, none of them convincing all of the core team members.

So, early in 2020, all IMWA members, journal authors and reviewers were asked to send outstanding mine water images to the Managing Editor. Of the 103 photographs that were sent in, 70 had the required technical quality, but only 47 showed mine water content. These were therefore 

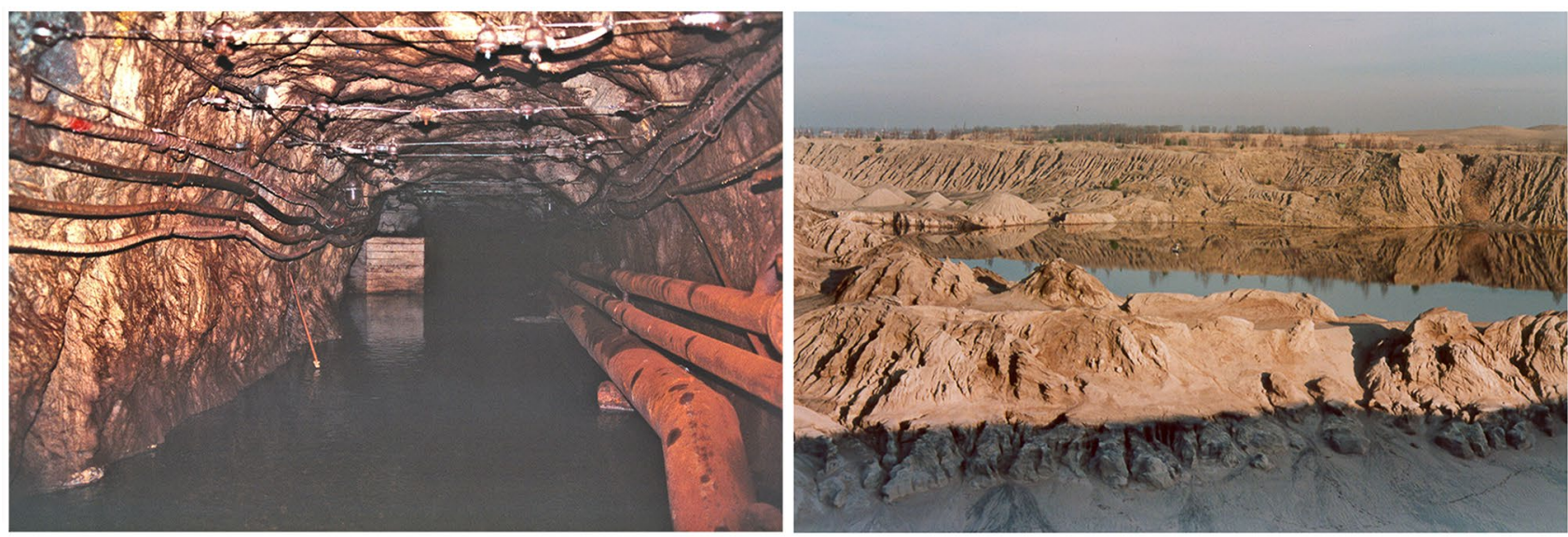

Fig. 4 Original images for the cover. Left: Niederschleam/Alberoda uranium mine, Germany, level-990 (photographer: Christian Wolkersdorfer 1994); right: Goitzsche open pit lignite mine, Germany (photographer: Robert Kringel 2000)

entered into a poll; 278 of you participated, and the first eight images of the 70 became quickly obvious. Of these, four will be shown on the front and the other four on the back of each individual issue in 2021 (Table 1, Fig. 5).
Because of the success of that effort, the Editors have decided that IMWA members should again choose the cover design in future years. Fritz Schmuhl, who is currently responsible for our journal at Springer Nature, agreed that

Table 1 Image authors of the eight selected mine water images for the 2021 covers of "Mine Water and the Environment"

\begin{tabular}{llll}
\hline Image Author & Votes & Percentage & Image Content \\
\hline Mike Moncur & 117 & $42 \%$ & Abandoned Cu-Zn mine, Manitoba, Canada \\
Peter Klampfl & 111 & $40 \%$ & Abandoned Chamosit iron mine, Schmiedefeld/Thuringia, Germany \\
Peter Klampfl & 104 & $38 \%$ & Abandoned Shale mine Kolditz/Thuringia, Germany \\
Eduardo Silva & 104 & $38 \%$ & La Corta Atalaya de Minas de Río Tinto, Spain \\
Mike Moncur & 93 & $34 \%$ & Abandoned Cu-Zn mine, Manitoba, Canada \\
Skousen/Kruse-Daniels & 83 & $30 \%$ & Quicklime doser results, Raccoon Creek, Ohio, USA \\
Frank Kremer & 82 & $30 \%$ & Harpen lake, receiving mine water from the Robert Müser coal mine, Bochum, Germany \\
Ulf Laube & 75 & $27 \%$ & AdventureCentre Röhrig shaft mine ('Grünes Gewölbe'), Wettelrode, Germany \\
\hline
\end{tabular}
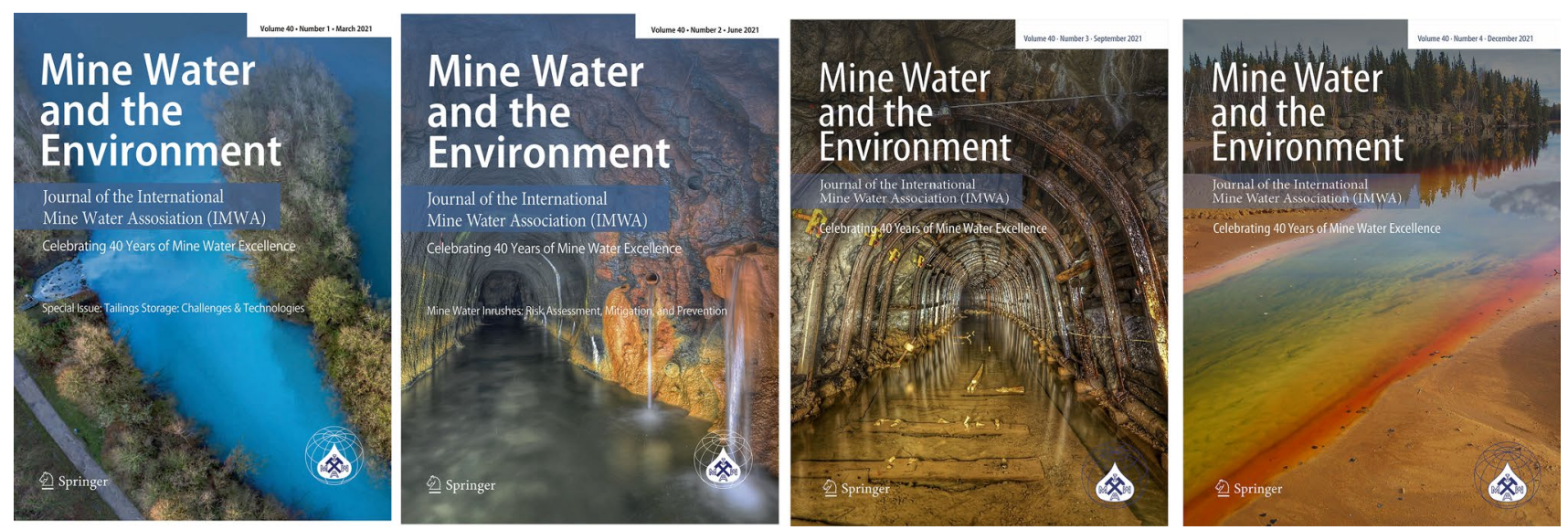

Fig. 5 Four cover images of "Mine Water and the Environment" in the 40th anniversary issue for 2021 (issues 3 and 4 are drafts) 
the journal can have a new cover every year. This will ensure that Mine Water and the Environment will continue to have an attractive cover in the future.

\section{The Future}

Writing about the future is like looking into the crystal ball—no one knows what will happen. The editorial team will do all that it can to satisfy your needs related to information on mine water, and will strive to maintain, if not improve, the journal's quality and its relevance to both researchers and practioners. However, ultimately, the quality of the journal depends on the type and quality of papers that it receives. Although we receive high numbers of manuscripts from China, most of these relate to mine water inrushes. Although this is a very serious problem in China and deserves an important place in this journal, it is not relevant to most of our readers outside of China. So, this is a special plea to all of you who are sitting on research results that you suspect would interest many of our readers, if you only had the time to write them up-please make the time! Mine Water and the Environment is currently in the top quartile of the world's water-related journals, but it will not remain there without your help. We need more enthusiastic authors, and while we are at it, enthusiastic reviewers, and editors. Equipped with these qualities, we look forward to another 40 volumes of Mine Water and the Environment.
Kleinmann B (2020a) Dear reader. Mine Water Environ 39(3):423-424. https://doi.org/10.1007/s10230-020-00708-4

Kleinmann B (2020b) Dear readers. Mine Water Environ 39(2):163164. https://doi.org/10.1007/s10230-020-00688-5

Li P, Qian H, Wu J, Zhang Y, Zhang H (2013) Major ion chemistry of shallow groundwater in the Dongsheng coalfield, Ordos Basin, China. Mine Water Environ 32(3):195-206. https://doi.org/10. 1007/s10230-013-0234-8

Li P, Wu J, Tian R, He S, He X, Xue C, Zhang K (2018) Geochemistry, hydraulic connectivity and quality appraisal of multilayered groundwater in the Hongdunzi coal mine, Northwest China. Mine Water Environ 37(2):222-237. https://doi.org/10.1007/ s10230-017-0507-8

Mudd GM (2008) Sustainability reporting and water resources: a preliminary assessment of embodied water and sustainable mining. Mine Water Environ 27(3):136-144. https://doi.org/10.1007/ s10230-008-0037-5

Prasad B, Sangita K (2008) Heavy metal pollution index of ground water of an abandoned open cast mine filled with fly ash: a Case Study. Mine Water Environ 27(4):265-267. https://doi.org/10. 1007/s10230-008-0050-8

Skousen J, Zipper CE, Rose A, Ziemkiewicz PF, Nairn R, McDonald LM, Kleinmann RL (2017) Review of passive systems for acid mine drainage treatment. Mine Water Environ 36(1):133-153. https://doi.org/10.1007/s10230-016-0417-1

Wolkersdorfer C (2002) Twenty years of the International Mine Water Association Journal-the First Issue. Mine Water Environ 21(2):100-101. https://doi.org/10.1007/s102300200025

Wolkersdorfer C (2004) Mine water literature in ISI's science citation index expanded ${ }^{\mathrm{TM}}$. Mine Water Environ 23(2):96-99. https://doi. org/10.1007/s10230-004-0046-y

Żurek R, Diakiv V, Szarek-Gwiazda E, Kosiba J, Wojtal AZ (2018) Unique pit lake created in an opencast potassium salt mine (Dombrovska Pit Lake in Kalush, Ukraine). Mine Water Environ 37(3):456-469. https://doi.org/10.1007/s10230-018-0527-z

\section{References}

Abaci S, Edwards JS, Whittaker BN (1992) Relative permeability measurements for two phase flow in unconsolidated sands. Mine Water Environ 11(2):11-26. https://doi.org/10.1007/BF02919583 